\title{
Milligram Per Kilogram Per Week
}

National Cancer Institute

\section{Source}

National Cancer Institute. Milligram Per Kilogram Per Week. NCI Thesaurus. Code

C161486.

A dose calculation unit expressed in milligram(s) per kilogram per period of time equal to seven days. 